\title{
Exploring Pro-environmental Behaviors among Thai People in Bangkok Metropolitan Region
}

\author{
W. Atthirawong and W. Panprung
}

\begin{abstract}
This paper focuses on the analysis of level of knowledge, awareness, and attitudes towards pro-environmental behaviors among people in Bangkok Metropolitan region. The sample study comprises of 326 respondents from 6 provinces in Thailand who had 15 years old and above which questionnaires were used as instrument of survey. The results of Pearson Correlation showed a significant relationship between awareness and attitude on pro-environmental behaviors among respondents. However, environment knowledge was not statistically significant correlated with other variables. Further analysis, Multiple Regression Analysis reveals a significant positive association between the respondents' pro-environmental behaviors and the two determinant factors i.e. attitudes and awareness. This study contributes to the literature by explaining the links between environmental awareness, attitudes, knowledge and real pro-environmental behaviors and defines the strength and direction among these variables. The findings generated from the study could help environmental management planners to establish policies and standards in order to encourage sustainable development.
\end{abstract}

Index Terms-Awareness, behavior, environment, knowledge, sustainable.

\section{INTRODUCTION}

Currently, environmental issues have become increasingly concerned by various countries across the globe due to depletion of natural resources, pollution problems and global warming. The consequences of global warming and climate changes can be appeared everywhere. Every organization pays greater attention to diminish the harmful impact of business activities in terms of production, consumption and purchasing behaviors on the environment. Environmental realization and concerns have led to the emergence of sustainable development which minimizes negative impact on the nature, physical environment and society [1]. Sustainable development has been given consideration as the ecological problems has become to the never-ending level over time. The key principle of sustainable development is to strengthen the economy and environment in long-term.

Regarding to the significant of environmental sustainability a society, consumers' participation in sustainable consumption is gained increased attention [2].

Manuscript received June 5, 2018; revised August 23, 2018. This work was supported in part by the National Research Council of Thailand (NRCT) the sponsor of this research funding.

W. Atthirawong is with the King Mongkut's Institute of Technology Ladkrabang, Department of Statistics, Bangkok, Thailand (e-mail: walailaknoi@gmail.com).

W. Panprung is with the Management Science Department, Phranakhon Rajabhat University, Bangkok, Thailand (e-mail: noiwari@gmail.com).
Nevertheless, environmental protection is one of the biggest global challenges in human society. Such challenge is individuals may think that environmental problems belong to the entire society which is not their personal concern. According statistical data from [3], more than 60 percent of all environmental impacts came from household consumption, and 80 percent of them occur during end use.

Governments of several countries in the world have undertaken the task of addressing much of this challenge by establishing policies and standards in order to decrease the production of $\mathrm{CO}_{2}$ and regulate the impacts of human activity to more sustainable lifestyle in households, educational intuition as well as companies [4]. However, for raising public awareness and enhancing sustainable behavior towards the environmental issues depend not only on the schemes implemented by regulatory bodies, but also on the daily choices made by individuals. Environmental education, knowledge, environmental awareness and behavior changes pay important role in solving environmental issues [5], [6]. As mentioned by [7], environmental knowledge is an underpinning in understanding the impact of human behaviors towards environment. Once people have environmental knowledge in them, it would impact in shaping attitude and changing their practices for the purpose of protecting the environment [8]. Nonetheless, some studies (e.g. [9]) argue that knowledge of environmental issues may not followed by environmentally favorable behaviors in many situations.

As mentioned by [10], there are varieties factors both internal and external which are either positive or negative affecting the behaviors of individuals in pro-environment. Such factors that contribute towards environmental preservation are awareness, the level of knowledge and individual's behavior in society. These factors become unity will apparent in a person's actions [10]. Likewise, it is vital to learn and understand about pro-environmental behaviors and what factors influence on it [11], in order to be able to act on them [12]. If there is no information regarding those issues, it is impossible, for instance, to design successful public awareness campaigns. Therefore, surveys of this type should be part of every assessment on environmental issues and should be able to provide information for fostering more sustainable development in the future. Regarding to the background above, this study aims to investigate pro-environmental behaviors of people in Bangkok Metropolitan region related to their environmental attitude and awareness and the level of knowledge. To achieve this aim, survey based on self-assessment was conducted. The followings are the objectives that guided this study:

1) To evaluate levels of environmental knowledge among 
people in Bangkok Metropolitan region.

2) To investigate the relationship between environmental knowledge, attitude and environmental awareness towards pro-environmental behaviors.

From this point of view, the paper begins by providing an introduction and background of this research. Subsequently, the methodology and the results from the quantitative study will be presented in Section II and III. Finally, the paper concludes with a discussion of the results, limitations and future scope of the study.

\section{RESEARCH METHODOLOGY}

\section{A. Population and Sample}

Population in this study refers to people in Bangkok Metropolitan region, who were of 15 years of age or more. Multi-stage sampling technique was employed by dividing Bangkok Metropolitan region into 6 main strata which includes Bangkok, Nakhon Pathom, Pathum Thani Nonthaburi, Samut Prakarn and Samut Sakhon provinces. According to [13], a sample size of 385 can be representative of the opinion. Proportion allocation in each stratum is then calculated and samples were collected by way of convenience sampling. The survey was conducted between February and March 2018. Complete questionnaires were returned and used to analyze data for 326 cases, representing 84.68 per cent of all queries collected.

\section{B. Research Instruments}

This research is a quantitative research with questionnaire created as a tool for measuring variables. The questionnaire was divided into five sections. The first section includes socioeconomic and demographic variables (inquiries about general information, activities for environmental protection and main barrier in protection environment in Thailand which consists of 14 queries. The second section is quires about knowledge and understanding about environmental protection which consists of 12 queries. The third section is inquires about pro-environmental behaviors. Each variable gauges according to 5-point Likert-type scale ranging from (1) never, (2) rarely (1-2 times in 10 times), (3) sometimes (3-6 times in 10 times), (4) often (7-9 times in 10 times), and (5) always (10 times). The fourth section focuses about attitude and environmental awareness. A question of 19 items was developed regarding literature review and previous studies. The respondents were asked to express their agreement or disagreement with a statement on 5-point Likert-type scale [14] ranging from (1) strongly disagree to (5) strongly agree. The final section is inquiries about opinions and ideas on how to promote environmental responsibilities in practices.

To assess the reliability of the research questionnaire, thirty sets of questionnaires were tested. Conbrach's Alpha Coefficient for the entire questions was $80.9 \%$, where was considered as reliability and acceptability, and could be used to collect data from the samplings. Data was analyzed by using both descriptive for analyzing personal data of sample group and inferential statistics i.e. Pearson's Correlation Coefficient and Multiple Regression Analysis were used for hypothesis testing through analyzing relationship of factors influencing pro-environmental behaviors.

\section{DATA ANALYSIS AND RESUlts}

\section{A. Mean and Standard Deviation of Variables}

The mean and standard deviation of environmental knowledge, attitude and awareness, pro-environmental behaviors are demonstrated in Table I. With respect to environmental knowledge, findings revealed that the respondents had moderate knowledge of the environment-related matters and information (Mean=7.546 out of 12 environmental knowledge questions). Regarding attitudes toward environmental issues, the respondents scored rather positive high attitudes (Mean=3.951). Furthermore, they seems had a bit high awareness on environment (Mean=4.205) as well. Likewise, the respondents' pro-environmental behaviors were in often level $($ Mean $=3.557)$.

TABLE I: MEAN AND STANDARD DEVIATION OF THE FOUR VARIABLES

\begin{tabular}{lccc}
\multicolumn{2}{c}{ TABLE I: MEAN AND STANDARD DEVIATION OF THE FOUR VARIABLES } \\
\hline \multicolumn{1}{c}{ Variables } & Mean & S.D. & Meaning \\
\hline Environment Knowledge & 7.546 & 1.337 & Moderate \\
Environment Attitude & 3.951 & 0.593 & High \\
Environment Awareness & 4.205 & 0.386 & Very high \\
Pro-environmental Behaviors & 3.557 & 0.474 & Often \\
\hline
\end{tabular}

\section{B. Pearson's Correlation Coefficient}

Pearson's correlation coefficient is employed to examine the linear relationship between the dependent variable (pro-environmental behaviors) and the three independent variables (knowledge, attitudes, and awareness). Table II demonstrates the results of the Pearson correlation analysis.

\begin{tabular}{lccc}
\multicolumn{3}{c}{ TABLE II: PEARSON CORRELATION ANALYSIS } \\
\hline & $\begin{array}{c}\text { Environment } \\
\text { Attitude }\end{array}$ & $\begin{array}{c}\text { Environment } \\
\text { Awareness }\end{array}$ & $\begin{array}{c}\text { Pro-environmental } \\
\text { Behaviors }\end{array}$ \\
\hline $\begin{array}{l}\text { Environment } \\
\text { Knowledge }\end{array}$ & -.001 & .012 & -.082 \\
$\begin{array}{l}\text { Environment } \\
\text { Attitude }\end{array}$ & $.341^{* *}$ & $.270^{* *}$ \\
$\begin{array}{l}\text { Environment } \\
\text { Awareness }\end{array}$ & & $.247^{* *}$ \\
\hline Note: ** Correlation is significant at the 0.01 level (2-tailed)
\end{tabular}

An analysis finds evidence that there were correlations separately between environment attitude, environment awareness and pro-environmental behaviors in a positive way but weak and statistically significant at 0.01 levels ( $p$-value < 0.01). However, environment knowledge was not statistically significant correlated with other variables.

\section{Multiple Regression Analysis}

Stepwise Multiple Regression was employed to this research to investigate the best predictors of pro-environmental behaviors. This methodology analytically adds the most significant variable or removes the least significant variable during each step and helps to interactively find out which predictors seem to provide a good fit. Table III illustrates the model summary and shows that the $\mathrm{R}^{2}$ value is 0.100 for the model that includes environment attitude, environment awareness and environmental knowledge as independent variables. The 
Durbin-Watson test resulted in a value of 1.854 , which is within the acceptable limit [15]. It means that there is not collinearity in the model of this study.

\begin{tabular}{lccccc}
\hline $\begin{array}{c}\text { TABLE III: ModEL SUMMARY } \\
\text { Mode }\end{array}$ & $\mathrm{R}$ & $\mathrm{R}^{2}$ & $\begin{array}{c}\text { Adjusted } \\
\mathrm{R}^{2}\end{array}$ & $\begin{array}{c}\text { Std. Error of } \\
\text { the Estimate }\end{array}$ & $\begin{array}{c}\text { Durbin- } \\
\text { Watson }\end{array}$ \\
\hline 2 & .316 & .100 & .094 & .451 & 1.854 \\
\hline \multicolumn{7}{c}{ TABLE VI: ANOVA TEST RESULT } \\
\hline \multicolumn{7}{c}{ Model } & $\begin{array}{c}\text { Sum of } \\
\text { Squares }\end{array}$ & df. & $\begin{array}{c}\text { Mean } \\
\text { Square }\end{array}$ & F & Sig. \\
\hline Regression & 7.299 & 2 & 3.650 & 17.955 & .000 \\
$\begin{array}{l}\text { Residual } \\
\text { Total }\end{array}$ & 65.653 & 323 & .203 & & \\
\hline
\end{tabular}

\begin{tabular}{lccccc}
\multicolumn{7}{c}{ TABLE V: MULTIPLE REGRESSION ANALYSIS RESULTS } \\
\hline \multicolumn{7}{c}{$\begin{array}{c}\text { UNSTANDARDIZED } \\
\text { COEFFICIENTS }\end{array}$} & $\begin{array}{c}\text { STANDA } \\
\text { RDIZED }\end{array}$ & T & SIG. \\
VARIABLES & $\mathrm{B}$ & $\begin{array}{c}\text { STD. } \\
\text { ERROR }\end{array}$ & BETA & & \\
\hline CONSTANT & 1.990 & .284 & & 6.999 & .000 \\
$\begin{array}{l}\text { Environment } \\
\text { Attitude } \\
\begin{array}{l}\text { Environment } \\
\text { Awareness }\end{array}\end{array}$ & .168 & .045 & .210 & 3.744 & .000 \\
\hline
\end{tabular}

Table IV presents the results from ANOVA test which found the statistically significant value at 0.000 (p-value $<0.01$ ) with the F-value of 17.955. It implies that the regression model is good fit for the data. Table $\mathrm{V}$ also shows standardized and unstandardized coefficients of each variable along with $\mathrm{t}$ statistics with the corresponding $\mathrm{p}$-values. It is implied that only the 2 independent variables i.e. environment attitude and environment awareness were significantly contributes to pro-environmental behaviors for people who live in Bangkok Metropolitan region. A coefficient also shows the higher the beta the most important factors of influence pro-environmental behaviors. It can be concluded that environment awareness is the most important factors that influence pro-environmental behaviors which having beta of 0.215 .

\section{CONCLUSION}

This study examined four environmental factors of people in Bangkok Metropolitan region: environmental knowledge, attitude, awareness and pro-environmental behaviors. The results of the study revealed that people in Bangkok Metropolitan region scored reasonable for attitude, awareness behaviors regarding environmental matters but moderate in knowledge. A positive relationship was found between the respondents' pro-environmental behaviors and the two determinant factors i.e. attitudes and awareness. Although the antecedent factors have significant influence on the dependent variable, regression analysis revealed that those two independent variables explained only $9.4 \%$ of the variations in the dependent variable and the other $90 \%$ of the determination of the respondents' environmental behaviors remains unexplained. More interestingly, the study found that knowledge of environmental did not influence on environmentally favorable behaviors and not correlate with other independent variables. The findings confirm earlier study of [9] about knowledge of environmental not reflecting environmentally favorable behaviors. This might be due to the level of knowledge of people in Bangkok Metropolitan region is still in moderate level. To increase the environmental knowledge of people there should be ways for instance the promotion of posters and electronic media related to environmental issues more frequently.

This study contributes to the literature by explaining the links between environmental awareness, attitudes, knowledge and real pro-environmental behaviors and defines the strength and direction among these variables. The findings generated from the study could help environmental management planners to establish policies and standards in order to encourage sustainable development in these issues. However, there are still some limitations for this study. The number of sample size is quite small compared to the whole population in the region. This study also investigates the pro-environmental behaviors in general. It might be examined in a specific behavior. In addition, future research should examine the effect of sample demographics (age, gender, education, and income) on the association between antecedent factors (knowledge, attitude, and awareness) using other methodologies. Similar studies should replicate this research with different segments of the population. Likewise, it is meaningful to continuously work in different scientific or using other tools for expanding scopes for example examine the relationships of information and strategies government of the six city councils and sustainability performance dimensions. Moreover, effort should be made in development of other methodological insights for minimizing the knowledge and pro-environmental behaviors gap of individuals in the region. Another aspect is to study the role of the media in creating environment awareness.

\section{ACKNOWLEDGMENT}

The author would like to thank National Research Council of Thailand (NRCT), the sponsor of this research funding. Appreciation also goes to all Bangkok Metropolitan respondents who participated in this survey and all survey teams who assisted in administrating surveys.

\section{REFERENCES}

[1] A. Walailak and P. Wariya, "A study on the consumers' buying behaviour towards product in Bangkok," Int. J. of Manag. and App. Sci., vol. 3, no. 11, pp. 26-31, 2017.

[2] (2011). Cone communications: Americans value honesty over perfection in environmental marketing. Research \& Insights. [Online]. Available: http://www.conecomm.com/2011- green-gap-blog-post

[3] (2010). United Nations Environment Programme (UNEP). Annual Report. [Online]. Available: http://www.sciepub.com/reference/188034

[4] O. Studynka, "Pro-environmental behaviour in the workplace," Wageningen University \& Research Centre Department of Social Sciences, 2013.

[5] H. R. Hungerford, W. J. Bluhm, T. L. Volk, and J. M. Ramsey, The Tbilisi Declaration Essential Readings in Environmental Education, 3rd Edition. Champaign, IL, Stripes Publishing, 2005.

[6] N, Hidaya and R. R. Agustin. (2017). Assessing high school students' pro-environmental behavior. Journal of Physics: Conf. Series. [Online]. Available: doi :10.1088/1742-6596/895/1/012002

[7] X. He, T. Hong, L. Liu, and J. Tiefenbacher, "A comparative study of environmental knowledge, attitudes and behaviours among university students in China," Int. Res. in Geo. and Envi. Edu., vol. 20, no. 2, pp. 91-104, 2011. 
[8] J. L. Elder, A Field Guide to Environmental Literacy: Making Strategic Investment in Environmental Education, Beverly, MA: Environmental Education Coalition, 2003.

[9] A. Proferl, K. Schilling, and K.W. Brand, Environmental Awareness and Everyday Actions, an Empirical Study Socio-cultural Orientations, Leske Budrich, Opladen, 1997.

[10] T. Palupi and D. R. Sawitri. (2018). The importance of pro-environmental behaviors in adolescent. E3S Web of Conferences 31. [Online]. Available: https://doi.org/10.1051/e3sconf/20183109031

[11] N. C. Bronfman et al., "Understanding attitudes and pro-environmental behaviors in a Chilean community," Sustainability, vol. 7, no. 10, pp. 14133-14152, 2015.

[12] J. Bruce, J. Lee, and E. Haites, "Economic and social dimensions of climate change," Contribution of Working Group III to the Second Assessment Report of the Intergovernmental Panel on Climate Change, Cambridge: Cambridge University Press, 1995.

[13] R. V. Krejcie and D. W. Morgan, "Determining sample size for research activities," Edu. and Psy. Meas. vol. 30, no. 3, pp. 607-610, 1970.

[14] L. Wolfer, Real Research Conducting and Evaluating Research in the Social Sciences, New Jersey: Pearson Education, Inc., 2007.

[15] J. Dubin and G. S. Watson, "Testing for serial correlation in least squares regression," Biometrika, vol. 38, no.1-2, pp. 159-178, 1951.

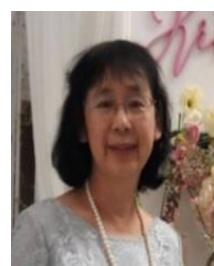

W. Atthirawong is associate professor of operations research at Faculty of Science, King Mongkut's Institute of Technology Ladkrabang (KMITL) in

Thailand. She had received the doctoral degree from the University of Nottingham in manufacturing engineering and operations management. She is actively engaged research in logistics and supply chain management simulation, multi-criteria decision making, applied statistics and optimization.

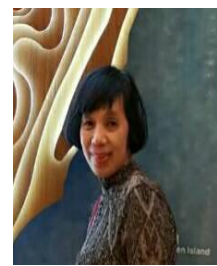

W. Panprung was born in Chonburi, Thailand. She had got her master degree from Srinakarinwirot University in accounting and Ramkhamheang University in business administrator. Now she is an assistant professor in management science at Phranakhon Rajabhat University. She is actively engaged research in accounting, applied statistics, logistics and supply chain management. 